Vol. 3 , 1, February, 2019

\title{
Non-invasive Monitoring of Brain Temperature during Rapid Selective Brain Cooling by Zero-Heat-Flux Thermometry
}

\author{
Mohammad Fazel Bakhsheshi a, b*, Marjorie Ho a, b, Lynn Keenliside a, \\ Ting-Yim Lee ${ }^{a, b, c}$ \\ ${ }^{a}$ Imaging Program, Lawson Health Research Institute, London, ON, Canada \\ ${ }^{b}$ Imaging Research Laboratories, Robarts Research Institute, London, ON, Canada \\ ${ }^{c}$ Department of Medical Imaging and Biophysics, The University of Western Ontario, London, ON, Canada
}

\begin{abstract}
Introduction: Selective brain cooling can minimize systemic complications associated with whole body cooling but maximize neuroprotection. Recently, we developed a non-invasive, portable and inexpensive system for selectively cooling the brain rapidly and demonstrated its safety and efficacy in porcine models. However, the widespread application of this technique in the clinical setting requires a reliable, non-invasive and accurate method for measuring local brain temperature so that cooling and rewarming rates can be controlled during targeted temperature management. In this study, we evaluate the ability of a zero-heat-flux SpotOn sensor, mounted on three different locations, to measure brain temperature during selective brain cooling in a pig model. Computed Tomography (CT) was used to determine the position of the SpotOn patches relative to the brain at different placement locations.

Methods and Results: Experiments were conducted on two juvenile pigs. Body temperature was measured using a rectal temperature probe while brain temperature with an intraparenchymal thermocouple probe. A SpotOn patch was taped to the pig's head at three different locations: $1-2 \mathrm{~cm}$ posterior (Location \#1, $\mathrm{n}=1$ ), central forehead (Location \#2, $\mathrm{n=1}$ ); and 1-2 cm anterior and lateral to the bregma i.e., above the eye on the forehead (Location $\# 3, n=1$ ). This cooling system was able to rapidly cool the brain temperature to $33.7 \pm 0.2^{\circ} \mathrm{C}$ within 15 minutes, and maintain the brain temperature within $33-34^{\circ} \mathrm{C}$ for $4-6$ hours before slowly rewarming to $34.8 \pm 1.1^{\circ} \mathrm{C}$ from $33.7 \pm 0.2^{\circ} \mathrm{C}$, while maintaining the core body temperature (as per rectal temperature probe) above $36^{\circ} \mathrm{C}$. We measured a mean bias of $-1.1^{\circ} \mathrm{C},-0.2^{\circ} \mathrm{C}$ and $0.7^{\circ} \mathrm{C}$ during rapid cooling in induction phase, maintenance and rewarming phase, respectively. Amongst the three locations, location \#2 had the highest correlation $\left(\mathrm{R}^{2}=0.8\right)$ between the SpotOn sensor and the thermocouple probe.

Conclusions: This SBC method is able to tightly control the rewarming rate within $0.52 \pm 0.20^{\circ} \mathrm{C} / \mathrm{h}$. The SpotOn sensor placed on the center of the forehead provides a good measurement of brain temperature in comparison to the invasive needle probe.
\end{abstract}

\section{Keywords:}

Brain Temperature;

Selective Brain Cooling;

Zero-Heat-Flux;

SpotOn;

Hypothermia;

Pig.
Article History:

$\begin{array}{llll}\text { Received: } & 15 & \text { September } & 2018 \\ \text { Accepted: } & 11 & \text { January } & 2019\end{array}$

\section{1- Introduction}

Hypothermia (brain temperature $<35^{\circ} \mathrm{C}$ ) shows great promise to prevent or minimize neural damage in patients with cardiopulmonary arrest and traumatic head injuries $[1,2]$. However, cooling the whole body below $33-34^{\circ} \mathrm{C}$ can induce severe complications [3]. Dysrhythmias, infections and primary coagulopathy are the most commonly noted complications [3]. In our group, we developed a Selective Brain Cooling (SBC) approach which can be initiated early, induces rapid cooling and maintains the target brain temperature over an extended period of time before slowly rewarming without significantly affecting the core body temperature [4]. This method works by blowing air produced by a vortex tube into the nostrils at a temperature range of -5 to $16^{\circ} \mathrm{C}$ and at flow rates of 5 to $45 \mathrm{~L} / \mathrm{min}$. In a recent paper

*CONTACT: Mfazelba@alumni.uwo.ca

DOI: http://dx.doi.org/10.28991/esj-2019-01163

(C) This is an open access article under the CC-BY license (https://creativecommons.org/licenses/by/4.0/). 
[4], we showed that blowing air cooled by the vortex tube intranasally is an effective and safe method to selectively lower and maintain brain temperature. The cooling system was capable of achieving brain temperature of less than approximately $34^{\circ} \mathrm{C}$ within $30-40 \mathrm{~min}$ and sustaining a brain-esophageal temperature difference of greater than about $3^{\circ} \mathrm{C}$ over 6 hours. The temperature and flow rate of the cold air stream are controlled continuously by a microprocessor and are regulated by a feedback system from the brain temperature. In our experiments, brain temperatures were measured invasively by inserting a thermocouple probe into the brain parenchyma, which provides accurate measurements but may be too invasive in a clinical setting, making it unsuitable for many patients. Invasive intracranial probes, such as those for intracranial pressure monitoring, carry potential complications such as intracranial hemorrhage or hematoma and infections [5]. Accordingly, we believe that the clinical adaptation of this technique requires a reliable, non-invasive and accurate method for measuring local brain temperature so that cooling and rewarming rates can be controlled during targeted temperature management.

Zero-heat-flux (ZHF) thermometry is an alternative, non-invasive method to measure core body temperature in human patients by applying a thermosensor patch to the lateral forehead. Recent studies by Eshraghi et al. and Iden et al revealed that the mean temperature difference between the new ZHF sensor (3M ${ }^{\mathrm{TM}}$ SpotOn, 3M, Neuss, Germany) on the forehead and the pulmonary artery catheter and nasopharyngeal temperatures was $0.23^{\circ} \mathrm{C}$ and $0.07^{\circ} \mathrm{C}$, respectively [6, 7]. These sensors consist of an insulator patch attached to the skin, which is covered by an electric heater that eliminates the heat loss to the environment, resulting in the formation of an isothermal tunnel subdermally to the skin surface. Therefore, temperature rising to the surface through this tunnel can be measured non-invasively and continuously.

Although there are promising results from recent studies, the ability of ZHF SpotOn sensor to monitor brain temperature during SBC has not been studied to our knowledge. Furthermore, ZHF thermometry's ability to measure temperature up to a depth of approximately $2 \mathrm{~cm}$ makes it a useful non-invasive tool for brain temperature monitoring. [8, 9] In the present study, we investigated whether brain temperatures measured by SpotOn sensor at different locations on the brain are accurate during SBC by comparing them with simultaneous measurements from a thermocouple inserted into the brain parenchyma of a pig model. The position of the SpotOn patches relative to the brain at different locations was determined by direct comparison with Computed Tomography (CT) measurement.

\section{2- Methods}

\section{2-1-Animal's Preparation and Experimental Procedure}

Experiments were conducted on two juvenile Duroc x Landrace crossbred pigs, approximately 2-3 months old with a weight of $21 \pm 11 \mathrm{~kg}$. All animal experiments were approved by the Animal Use Subcommittee of the Canadian Council on Animal Care at our institution. The surgical procedure has been presented in detail elsewhere.10 Body temperature was measured continuously using an esophageal temperature probe attached to the Surgivet monitor (Temperature probe WWV3418, Smiths Medical, Dublin, OH USA). Brain temperature was also measured continuously with a thermocouple probe. A $15-\mathrm{mm}$ burr hole was drilled in the skull $1.5 \mathrm{~cm}$ posterior and $1.5 \mathrm{~cm}$ lateral to the bregma along the mid-line with a Dremel tool. The thermocouple probe was inserted through the burr hole into the brain to a depth of $\approx 1 \mathrm{~cm}$ from the brain surface to measure brain temperature. A SpotOn patch was taped to the pig's head on three different locations; 1-2 $\mathrm{cm}$ posterior (Location \#1, $\mathrm{n}=1$ ), Centered on the forehead (Location $\# 2, \mathrm{n}=1$ ); and1-2 $\mathrm{cm}$ anterior and lateral to the bregma i.e., above the eye on the forehead (Location \#3, $n=1$ ).

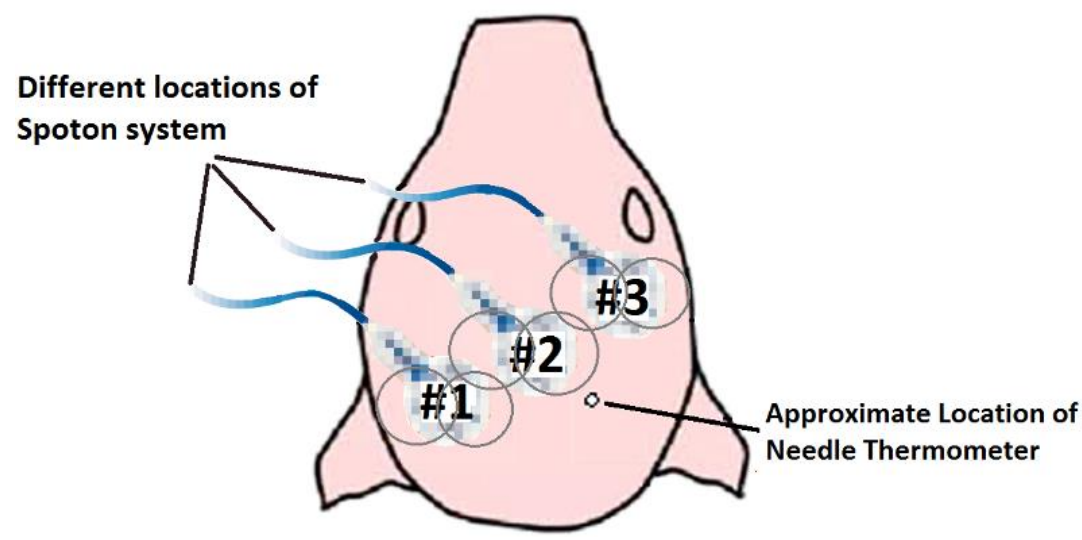

(a) 


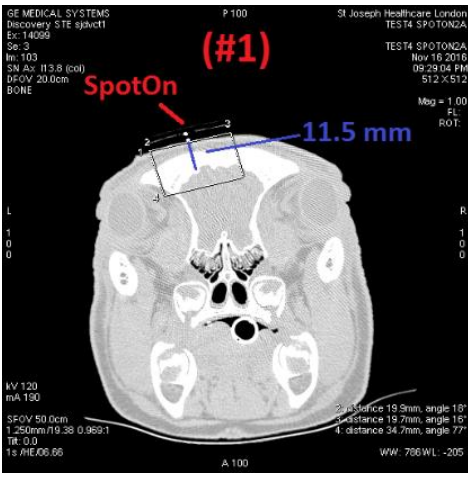

(b)

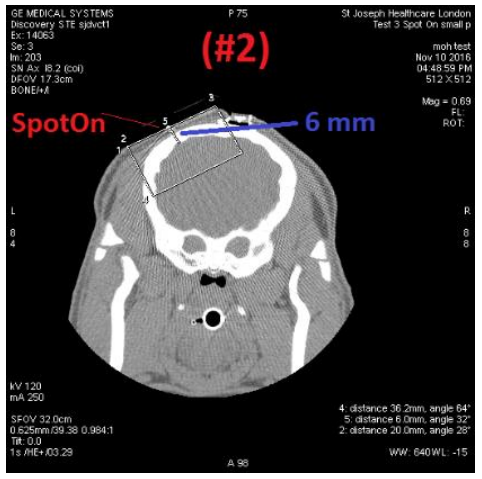

(c)

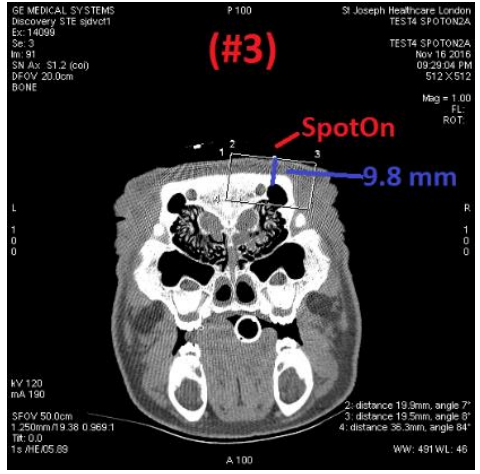

(d)

Figure 1. (a) Schematic of a pig's head showing the different approximate locations (\#1-3) of the SpotOn patches and estimated position of the needle thermocouple probe to measure brain temperature. (b-d) Coronal CT images showing the location of center of SpotOn patches and extra cerebral tissue i.e., scalp and skull thickness associated with each location. White lines in rectangle shape shows the region of interest below the whole SpotOn patch.

Figure 1(a) shows the schematic of a pig's head with the locations of the SpotOn temperature monitoring system as well as the thermocouple probe. A specific feature of the patch is its flexible material and electronic device, which enables the sensor to follow the contours of the skin surface. This prevents the occurrence of air pockets between sensor and skin and optimizes thermal contact. After the stabilization period, intranasal brain cooling was initiated by blowing cold air $\left(-3 \pm 2^{\circ} \mathrm{C}\right)$ at a flow rate of $45-50 \mathrm{~L} / \mathrm{min}$ into both nostrils from a medical air cylinder. After about 30 minutes, the source of compressed air was switched from the medical air cylinder to the hospital medical air for the maintenance and rewarming phases. Once the brain temperature was stabilized at the target temperature of $35.5 \pm 0.5^{\circ} \mathrm{C}$ as measured by the intracranial thermocouple, the flow rate and temperature were self-adjusted by the controller to maintain the brain at target temperature for 4-6 hours while core body temperature (i.e., rectal temperatures) was maintained above $36^{\circ} \mathrm{C}$ using the heated recirculating water pad and by packing gloves filled with hot water around the body of the pig within the linen blanket. During the rewarming phase, the brain temperature was gradually allowed to reach a temperature of $360 \mathrm{C}$ at a rewarming rate of $0.5^{\circ} \mathrm{C} / \mathrm{hr}$ by increasing the air temperature gradually and adjusting the flow rate. Active warming was performed during both maintenance and rewarming periods. Each experiment was completed within 1314 hours and the animals were sacrificed with intravenous potassium chloride $(1-2 \mathrm{ml} / \mathrm{kg}, 2 \mathrm{mEq} / \mathrm{mL})$ infusion.

\section{2-2-CT Data Acquisition}

Following experiment, pigs were placed in a Light Speed 64-slice CT scanner (GE Healthcare, Waukesha, WI, and U.S.A). A scout CT scan was performed to assess the position of the SpotOn patches relative to the brain in three different locations. Each scan provided eight contiguous $5 \mathrm{~mm}$ thick coronal slices, with a field of view $(12 \mathrm{~cm})$ set to encompass the entire head and snout of the pigs, in a prone position. Figure 1(b-d) shows cross-sectional anatomical CT image showing the position of center of SpotOn patches and extra cerebral tissue i.e., scalp and skull thickness, at all three locations (\#1-3).

\section{2-3-Statistical Analysis}

SPSS 17.0.0 (SPSS, Inc, Chicago, IL) was used for all statistical analyses. Monitored physiologic parameters and vital signs were analyzed by repeated measures ANOVA. Finally, the degree of similarity between temperature measurements acquired with the two techniques was evaluated using a Bland-Altman plot, to calculate the bias and $95 \%$ limit of agreement [10]. Statistical significance was based on $p$-value $<0.05$. All data are presented as mean \pm standard deviation (SD) unless otherwise noted.

\section{3- Results}

Table 1 displays a summary of the physiological parameters (mean \pm SD) of 3 pigs measured at different stages of the experiment: baseline, hypothermia maintenance (at target brain temperature of $33 \pm 1^{\circ} \mathrm{C}$ ) and rewarming (at target rate of $0.5^{\circ} \mathrm{C} / \mathrm{hr}$ ). As shown in Figure 1(B-D), the skull thickness underneath the SpotOn sensor measured from CT images at all three locations (\#1-3) was $11.5 \mathrm{~mm}, 6 \mathrm{~mm}$, and $9.8 \mathrm{~mm}$, respectively.

\section{Physiological parameters measured at different brain temperatures}

Mean arterial pressure (MAP) dropped slowly after the induction of intranasal cooling from $63 \pm 16$ to $54 \pm 8 \mathrm{mmHg}$, however, during rewarming, when the brain temperature reached $35.5 \pm 0.3^{\circ} \mathrm{C}$, MAP increased to $60 \pm 20 \mathrm{mmHg}$. Total hemoglobin $(t H b)$ and serum potassium $\left(c K^{+}\right)$levels, measured by arterial blood gas samples, gradually increased from 
baseline at $8.1 \pm 0.1 \mathrm{~g} / \mathrm{dL}$ and $3.7 \pm 0.4 \mathrm{mmol} / \mathrm{L}$ to $9.1 \pm 0.4 \mathrm{~g} / \mathrm{dL}$ and $6.0 \pm 0.5 \mathrm{mmol} / \mathrm{L}$ after the cooling and rewarming inclusively. Other measured physiologic parameters were stable and within normal limits throughout the experiment.

Table 1. Physiological parameters (mean \pm standard deviation (SD)) measured at different brain temperatures at baseline and during cooling and rewarming. $\mathrm{cNa}^{+}$- sodium concentration, $\mathrm{cK}^{+}$- potassium concentration, $\mathrm{cCa}^{+}$- calcium concentration, $\mathrm{cCl}^{-}$- chloride concentration, $\mathrm{tHb}$ - total hemoglobin concentration, and $\mathrm{P}_{\mathrm{a}} \mathrm{CO}_{2}$ - partial pressure of carbon dioxide was measured in arterial blood samples. MAP - mean arterial pressure - HR - heart rate was measured from a femoral artery catheter. *A statistically significant $(\mathbf{p}<0.05)$ change compared to baseline

\begin{tabular}{|c|c|c|c|}
\hline & Baseline & Cooling \& Maintenance phase & Rewarming phase \\
\hline Brain Temp $\left({ }^{\circ} \mathrm{C}\right)$ & $38.2 \pm 0.1$ & $33.6 \pm 1.1$ & $35.5 \pm 0.3$ \\
\hline$c \mathrm{Na}^{+}(\mathrm{mmol} / \mathrm{L})$ & 145 & $141 \pm 1$ & $143 \pm 7$ \\
\hline$c K^{+}(\mathrm{mmol} / \mathrm{L})$ & $3.7 \pm 0.4$ & $4.6 \pm 0.6^{*}$ & $6.0 \pm 0.5^{*}$ \\
\hline$c \mathrm{Ca}^{2+}(\mathrm{mmol} / \mathrm{L})$ & 1.3 & 1.3 & 1.3 \\
\hline $\mathrm{cCl}(\mathrm{mmol} / \mathrm{L})$ & $107 \pm 2$ & $104 \pm 2$ & $103 \pm 1$ \\
\hline$M A P(m m H g)$ & $63 \pm 16$ & $54 \pm 8$ & $60 \pm 20$ \\
\hline HR (bpm) & $108 \pm 13$ & $99 \pm 25$ & $111 \pm 16$ \\
\hline$p H$ & 7.5 & 7.5 & 7.5 \\
\hline$t H b(g / d L)$ & $8.1 \pm 0.1$ & $8.6 \pm 0.4$ & $9.1 \pm 0.4^{*}$ \\
\hline $\mathrm{P}_{a} \mathrm{CO}_{2}(\mathrm{mmHg})$ & $40 \pm 2$ & $38 \pm 2$ & $37 \pm 2$ \\
\hline
\end{tabular}

\section{Temperatures (esophageal, rectal, brain and SpotOn)}

Figure 2(a) shows the rectal and brain temperature profile as a function of time measured every 5 minutes. Brain temperature was obtained from intracranial thermocouple probe and a SpotOn temperature monitoring system in location \#1, in which the SpotOn patch was stuck on 1-2 cm posterior and 1-2 cm lateral to the bregma. During baseline, the pig had an average brain and rectal temperature of $38.2^{\circ} \mathrm{C}$ and $38.1{ }^{\circ} \mathrm{C}$, respectively. Following baseline, brain temperature measured by thermocouple probe dropped rapidly to $33.5^{\circ} \mathrm{C}$ within $20-25$ minutes and then stabilized at $33.7 \pm 0.2^{\circ} \mathrm{C}$ within the first hour of brain cooling. Following 4 hours of cooling, the brain was then allowed to gradually rewarm from $33.8^{\circ} \mathrm{C}$ to $35.8^{\circ} \mathrm{C}$ in 5 hours, corresponding to a rewarming rate of $0.4^{\circ} \mathrm{C} / \mathrm{h}$. During the whole experiment, the core temperatures were kept above $36^{\circ} \mathrm{C}$ using a recirculating heated water blanket.

During 10-15 minutes of cooling induction, the maximum thermocouple to SpotOn brain temperature gradient was $1.7^{\circ} \mathrm{C}$. During maintenance and rewarming phases, the temperature difference measured by thermocouple probe and SpotOn was $0.1 \pm 0.5^{\circ} \mathrm{C}$ and $0.9 \pm 5^{\circ} \mathrm{C}$, respectively. From the Bland-Altman analysis shown in Figure 2(b), the mean difference between the two methods (i.e., thermocouple vs SpoOn) throughout the whole experiment was $0.4^{\circ} \mathrm{C}$. The $95 \%$ confidence limits of the difference between the two methods were from -0.9 to $1.7^{\circ} \mathrm{C}$.

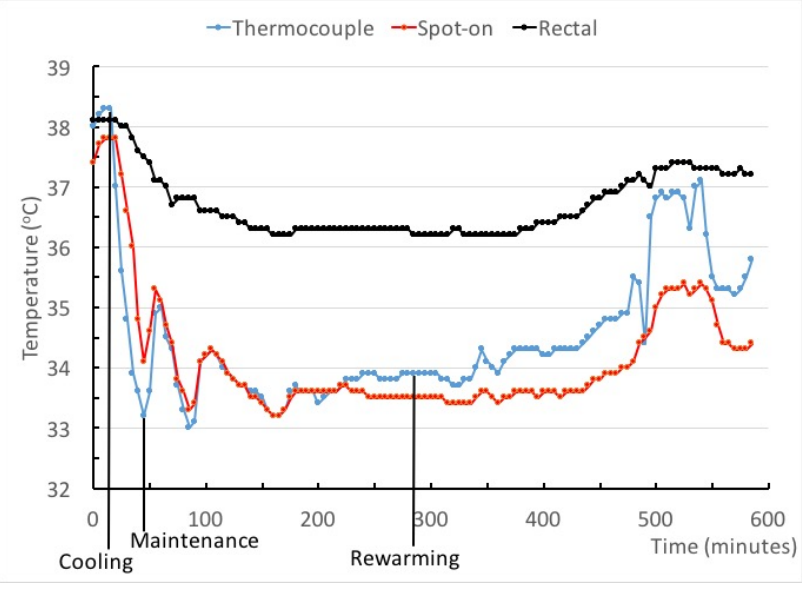

(a)

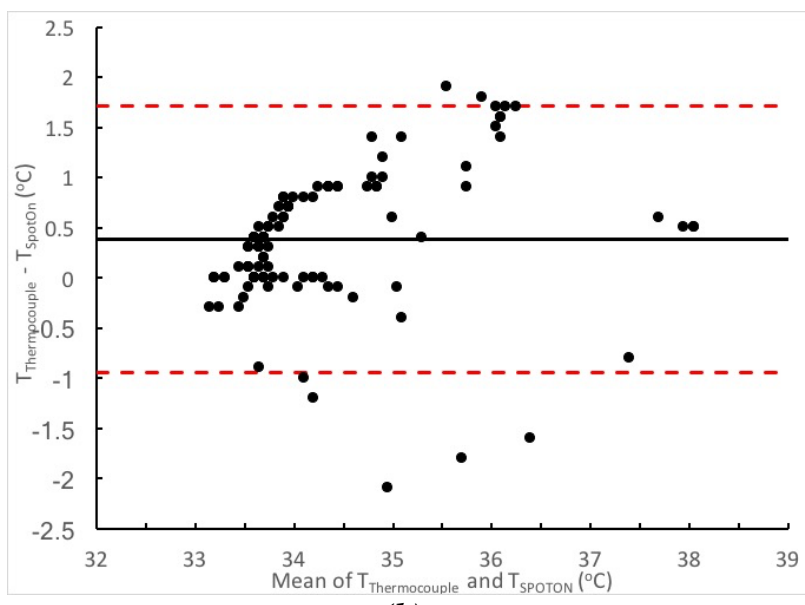

(b)

Figure 2. (a) Measured brain and rectal temperature over time during baseline, cooling/maintenance and rewarming phase. Brain data were obtained from thermocouple needle probe and SpotOn temperature monitoring system in location \#1, in which the SpotOn patch was stuck on 1-2 cm posterior and 1-2 cm lateral to the bregma. (b) Bland-Altman plot of two brain temperature methods. The dotted line shows the mean difference and dash-dotted lines show the limits of agreement (mean $\pm 2 \mathrm{SD})$. 
Figure 3(a) shows the brain and rectal temperature versus time plot on the same pig using SpotOn at location \#3 where the patch was stuck 1-2 cm anterior and lateral to the bregma i.e., above the eye on the forehead. Results of comparing brain temperature measured by two methods, reveal that after the initiation of rewarming, a thermocouple-SpotOn brain temperature gradient began to increase. From the Bland-Altman analysis in Figure 3(b), the mean difference between the two methods was $0.2^{\circ} \mathrm{C}$. The $95 \%$ confidence intervals of the difference between the two were $-1.8^{\circ} \mathrm{C}$ to $2.2^{\circ} \mathrm{C}$.

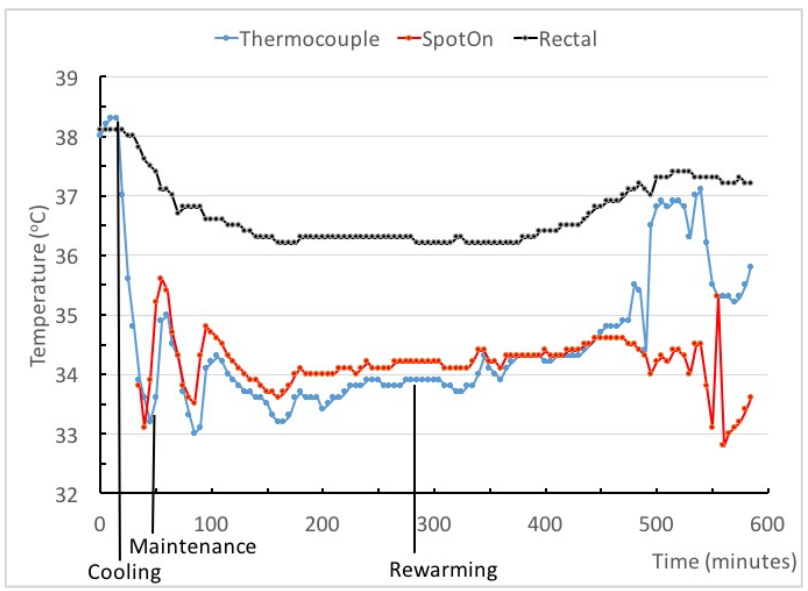

(a)

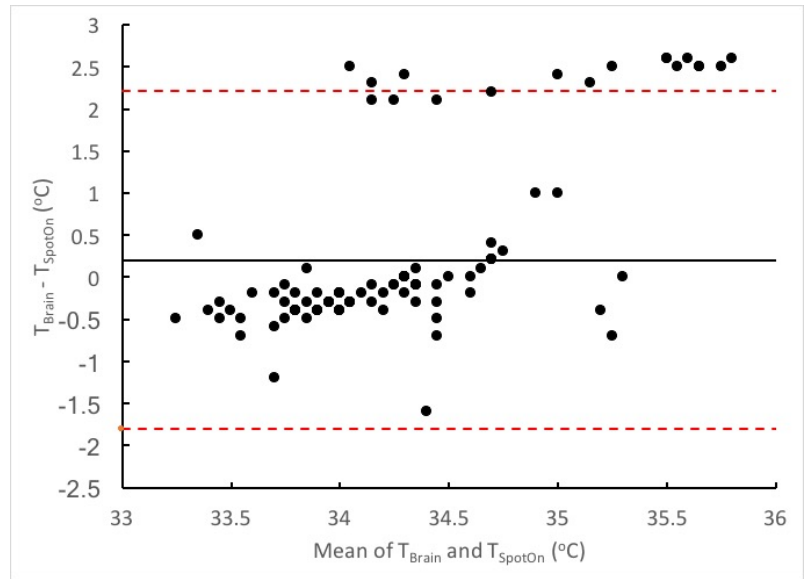

(b)

Figure 3. (a) Measured brain, rectal and esophageal temperature over time during baseline, cooling and rewarming phase. Brain data were obtained from thermocouple needle probe and SpotOn temperature monitoring system above the eye on the forehead (location \#3). (b) Bland-Altman plot of two brain temperature methods. The dotted line shows the mean difference and dash-dotted lines show the limits of agreement (mean \pm 2 SD).

Figure 4(a) shows the brain temperature versus time plot of needle probe and SpotOn sensor at the center of the forehead (location \#2) under the same cooling condition. By placing the SpotOn patch at this location to monitor brain temperature, the mean difference between the two temperature methods was $0.03{ }^{\circ} \mathrm{C}$ as shown in Figure 4 (b). The $95 \%$ confidence limits of the difference between the two methods were from -1.2 to $1.3^{\circ} \mathrm{C}$.

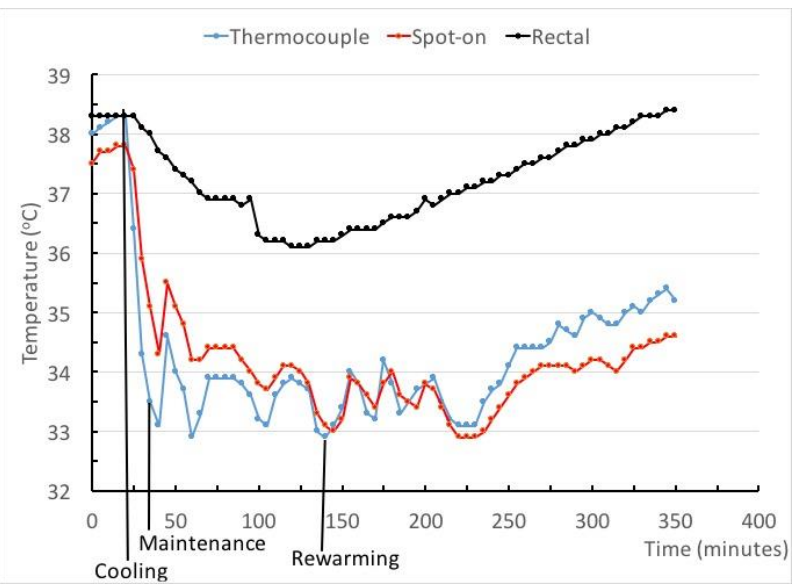

(a)

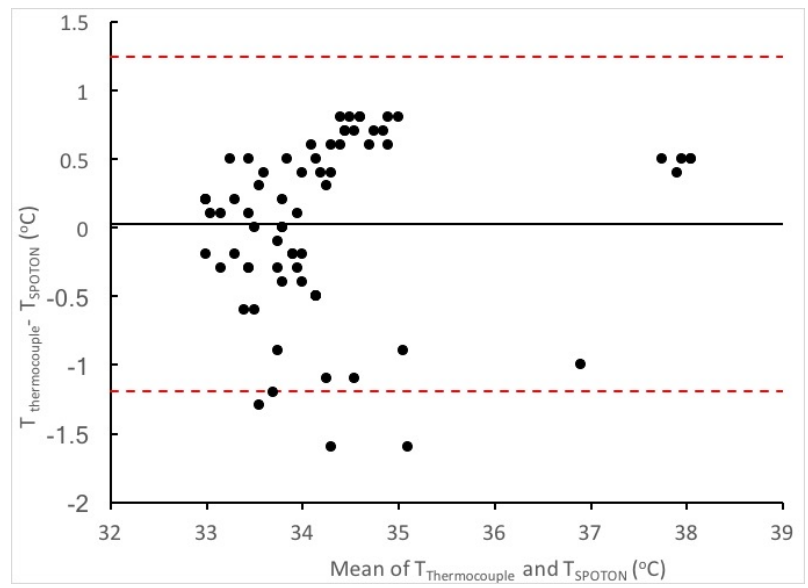

(b)

Figure 4. (a) Measured brain, rectal and esophageal temperature over time during baseline, cooling and rewarming phase. Brain data were obtained from thermocouple needle probe and SpotOn temperature monitoring system at the center of forehead (location \#2). (b) Bland-Altman plot of two brain temperature methods. The dotted line shows the mean difference and dash-dotted lines show the limits of agreement (mean $\pm 2 \mathrm{SD}$ ).

Figure 5 shows the correlation plot of the needle probe against SpotOn brain temperature of the all experiments. The average slope and $\mathrm{R}^{2}$ value from the regression analyses for location 1 were 0.6 and 0.7 ; for location 2 were 0.8 and 0.8 ; and for location 3 were 0.06 and 0.02 , respectively. 


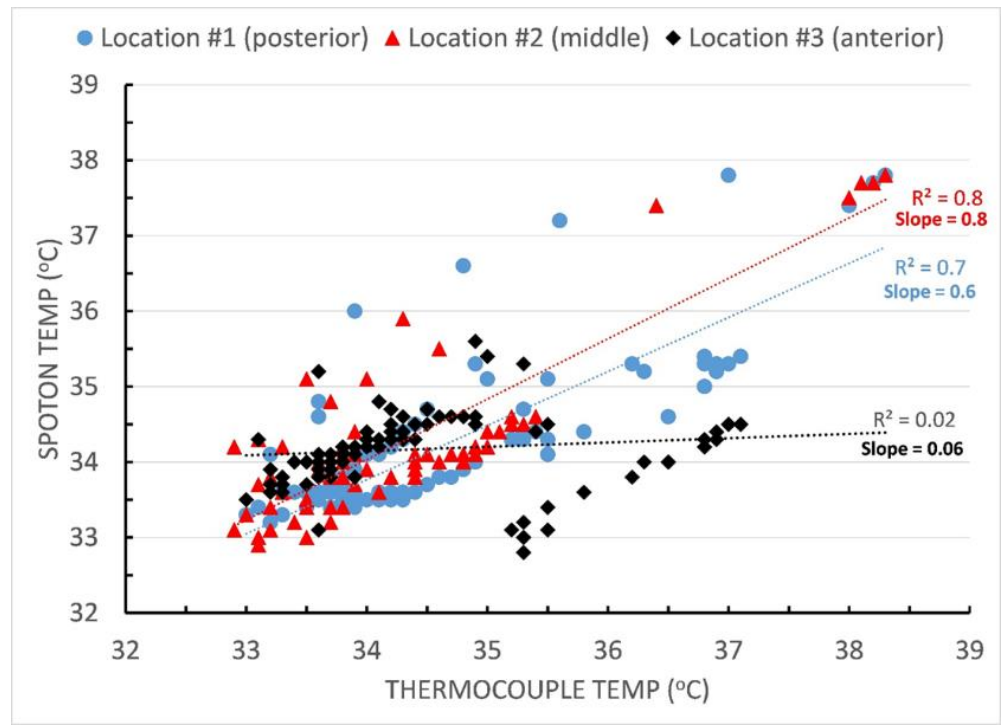

Figure 5. Correlation plot comparing two brain temperature methods using thermocouple needle probe and SpotOn patch sensor placed at three different locations on the pig's head. Each symbol type represents data from one of three locations.

\section{4- Discussion}

Reliable continuous brain temperature measurement is of major importance for monitoring patients. Assaults to the brain caused by ischemia, infarction or acquired brain injury causes the brain temperature to rise above body temperature. A typical elevation is between $1-2^{\circ} \mathrm{C}[11,12]$. A disadvantage to using intracranial thermocouple probe is the requirement for surgery for probe placement. Therefore, having a method to measure brain temperature non-invasively is extremely useful and important at an early stage to guide appropriate management. Besides this, SBC requires a method that can measure local brain temperature rather than body temperature as the latter may not reflect the actual brain temperature. Several approaches have been developed to assess brain temperature using different modalities such as optics [13, 14], magnetic resonance spectroscopy [15], ultrasound [16], microwave radiometry [17], ZHF technique.[18] However, these techniques have their shortcomings from practical issues such as complexity, increase in brain temperature during its operation [9,16] poor temporal and spatial resolution[19] sensitive to positioning errors [20] and delay in temperature measurement [21]. However, new technical breakthroughs in ZHF methods are promising and can potentially fulfil the advantages of non-invasiveness, reliability and short delay time that current measurement methods lack. Recently, Guschlbauer et al (2016) tested a SpotOn sensor in a porcine hypothermia model. Compared to temperature at pulmonary artery, there was a mean difference of $0.21 \pm 0.16^{\circ} \mathrm{C}$ and $0.21 \pm 0.16^{\circ} \mathrm{C}$ during rapidly changing temperature and stable temperature, respectively, when the patch was placed directly behind the eye. However, the study only investigated the accuracy of SpotOn measurement, with comparison to pulmonary artery, during cooling and maintenance under the condition of whole-body cooling. In the present study, we investigated the ability of SpotOn to measure brain temperature during SBC. Moreover, another important aspect which was not tested in their experiments is examining the SpotOn sensor during rewarming. Rewarming is a critical phase of therapeutic hypothermia to monitor for oxidative stress $[22,23]$. Rapid rewarming of the injured brain commonly leads to a mismatch between cerebral metabolism and perfusion [23] and can result in a rebound in intracranial pressure elevations [24], cerebral venous desaturation [22], and brain ischemia. It is suggested that controlling the rewarming rate to $0.1-0.3^{\circ} \mathrm{C} / \mathrm{hour}$ with an absolute maximum target of $0.5^{\circ} \mathrm{C}$ is preferred to reduce the neurological risks [25-27]. Therefore, we evaluate the ability of the SpotOn to measure brain temperature during rewarming using our SBC method in a pig model.

In this study, we showed that our method is able to tightly control the rewarming rate of brain within $0.52 \pm 0.20^{\circ} \mathrm{C} / \mathrm{h}$, by automatically adjusting the flow rate and temperature of cold air according to the invasive needle probe temperature. During the cooling induction and maintenance phases, both the brain and rectal temperature profiles were similar to those shown in previous studies by our group [4, 28], demonstrating the reproducibility of this nasopharyngeal brain cooling method. This cooling system was able to rapidly cool the brain temperature to $33.7 \pm 0.2^{\circ} \mathrm{C}$ within 15 minutes, and maintain the brain temperature within $33-34^{\circ} \mathrm{C}$ for $4-6$ hours before slowly rewarming to $34.8 \pm 1.1^{\circ} \mathrm{C}$ from $33.7 \pm$ $0.2^{\circ} \mathrm{C}$, while maintaining the core body temperature (as per rectal temperature probe) above $36^{\circ} \mathrm{C}$. These show the effectiveness of this device to cool the brain rapidly to the targeted hypothermic temperature, maintain it and control the rewarming rate tightly. Core body temperature was measured by both rectal and esophageal temperature probe. However, only rectal temperature values are presented. The temperature difference between rectal and esophageal was examined in both experiments and was less than $0.5^{\circ} \mathrm{C}$, which was consistent with our previous findings [4]. 
Moreover, we compared brain temperature measured by intracranial thermocouple probe to SpotOn sensor placed at three different locations on the pig's head. The thermocouple probe was inserted into the brain parenchyma at an average depth of $1.1 \pm 0.1 \mathrm{~cm}$. Amongst the three locations, location \#2 had the highest correlation $\left(\mathrm{R}^{2}=0.8\right)$ between SpotOn sensor and the thermocouple probe, with a slope of 0.8 (Figure 5). There are several factors that can explain this discrepancy. One explanation is the thickness of the skull underneath of the whole patch was thinner in location \#2 as verified by CT images. Second, at location \#2, the region underneath the SpotOn sensor had a homogenous geometry. The error in the brain temperature measurements by SpotOn sensor caused by incorrect region selection can also be explained by the differences between two techniques. The area under Location \#3 consists of sinus and brain tissue. This could explain the greater temperature difference between that measured by the intracranial needle probe and SpotOn during the rewarming phase.

The average difference between the two methods of temperature measurement was $0.3^{\circ} \mathrm{C}$. Regardless of the location, the bias during the induction and rewarming phases were significantly higher compared to the maintenance phase at all three locations (\#1-3). We measured a mean bias of $-1.1^{\circ} \mathrm{C},-0.2^{\circ} \mathrm{C}$ and $0.7^{\circ} \mathrm{C}$ during rapid cooling in induction phase, maintenance and rewarming phase, respectively. This discrepancy is likely a result of time delay in the formation of an isothermal pathway under the patch sensor through layers of the skin, skull and brain tissue at different phase of cooling. In this experiment, we found that at all locations (\#1-3), it took the SpotOn 10-25 minutes to attain a temperature measurement difference of less than $0.5^{\circ} \mathrm{C}$ from the intracranial thermocouple probe.

All monitored physiologic variables except for MAP, $\mathrm{HR}$, tHb and potassium were unchanged from baseline values throughout the cooling, maintenance and rewarming phases. A reduction in HR and MAP observed after the induction of intranasal cooling, may be due to physiological instabilities such as thermoregulatory responses to a decline in body temperature, such as the effects of cold-induced vasoconstriction, reduction of MAP and cardiac output [29]. The anesthetic level of isoflurane concentration (1-2\%) and propofol infusion rate $(30-50 \mathrm{ml} / \mathrm{hr})$ were adjusted when hyperkalemia was noted as per arterial blood gas samples that were taken during the experiment. No other management was done for hyperkalemia and the pigs in the study did not develop arrhythmia during hyperkalemic events. $\mathrm{pH}, \mathrm{PaO} 2$ and $\mathrm{PaCO}_{2}$ values were corrected for the body temperature to account for changes in $\mathrm{pH}, \mathrm{O}_{2}$ and $\mathrm{CO}_{2}$ blood levels with changing temperature [30, 31]. For example if correcting for hypothermia, for every degree below $37^{\circ} \mathrm{C}, 0.0012$ units was added to the $\mathrm{pH}$ value, $5 \mathrm{mmHg}$ and $2 \mathrm{mmHg}$ were subtracted from the $\mathrm{PaO} 2$ and $\mathrm{PaCO} 2$ respectively [30, 31].

\section{5- Conclusion}

In conclusion, the SpotOn sensor provides a good measurement of brain temperature in comparison to the invasive needle probe. In future studies, the ability of the SpotOn device to control the cooling and rewarming rate should be explored. As well, more experimental studies are necessary to evaluate the efficiency of the device and reproducibility of the results in different animal models of normal and injured brain. We plan on upgrading our controller to automatically adjust the flow rate and temperature of cold air according to the SpotOn temperature by placing the patch on the centre of the forehead.

\section{6- Acknowledgments}

The authors would like to thank Laura Morrison, and Jennifer Hadway for their help in conducting the animal experiments.

\section{7- Funding}

Funding for the experiments was provided by the Lawson Health Research Institute and Robarts Research Institute.

\section{8- Conflict of Interest}

M.F.B., L.K., and T.-Y.L. are inventors on the patent application PCT/CA2015/050216 submitted on March 4, 2014 describing the selective brain cooling method.

\section{9- Ethical Approval}

This work involved the use of experimental animals and the study therefore had ethical approval from Canadian Council on Animal Care.

\section{0- References}

[1] Arrich, Jasmin, Michael Holzer, Christof Havel, Marcus Müllner, and Harald Herkner. "Hypothermia for Neuroprotection in Adults after Cardiopulmonary Resuscitation." Cochrane Database of Systematic Reviews (February 15, 2016). doi:10.1002/14651858.cd004128.pub4. 
[2] Dietrich, W. Dalton, and Helen M. Bramlett. "Therapeutic Hypothermia and Targeted Temperature Management in Traumatic Brain Injury: Clinical Challenges for Successful Translation.” Brain Research 1640 (June 2016): 94-103. doi:10.1016/j.brainres.2015.12.034.

[3] Schubert, Armin. “Side Effects of Mild Hypothermia.” Journal of Neurosurgical Anesthesiology 7, no. 2 (April 1995$)$ : $139-147$. doi:10.1097/00008506-199504000-00021.

[4] Fazel Bakhsheshi, Mohammad, Yong Wang, Lynn Keenliside, and Ting-Yim Lee. "A New Approach to Selective Brain Cooling by a Ranque-Hilsch Vortex Tube.” Intensive Care Medicine Experimental 4, no. 1 (September 29, 2016). doi:10.1186/s40635016-0102-5.

[5] Raboel, P. H., J. Bartek, M. Andresen, B. M. Bellander, and B. Romner. "Intracranial Pressure Monitoring: Invasive Versus NonInvasive Methods-A Review.” Critical Care Research and Practice 2012 (2012): 1-14. doi:10.1155/2012/950393.

[6] Eshraghi, Yashar, Vivian Nasr, Ivan Parra-Sanchez, Albert Van Duren, Mark Botham, Thomas Santoscoy, and Daniel I. Sessler. “An Evaluation of a Zero-Heat-Flux Cutaneous Thermometer in Cardiac Surgical Patients.” Anesthesia \& Analgesia 119, no. 3 (September 2014): 543-549. doi:10.1213/ane.0000000000000319.

[7] Iden, T., E.P. Horn, B. Bein, R. Bohm, J. Beese, and J. Hocker, "Intraoperative temperature monitoring with zero heat flux technology (3M SpotOn sensor) in comparison with sublingual and nasopharyngeal temperature: An observational study." Eur J Anaesthesiol, 32, no. 6 (Oct 2015): 387-91. doi:10.1097/eja.0000000000000344.

[8] Guschlbauer, Maria, Alexandra C. Maul, Xiaowei Yan, Holger Herff, Thorsten Annecke, Anja Sterner-Kock, Bernd W. Böttiger, and Daniel C. Schroeder. "Zero-Heat-Flux Thermometry for Non-Invasive Measurement of Core Body Temperature in Pigs." Edited by Ulrike Gertrud Munderloh. PLOS ONE 11, no. 3 (March 3, 2016): e0150759. doi:10.1371/journal.pone.0150759.

[9] Brajkovic, Dragan, and Michel B. Ducharme. "Confounding Factors in the Use of the Zero-Heat-Flow Method for Non-Invasive Muscle Temperature Measurement.” European Journal of Applied Physiology 94, no. 4 (April 28, 2005): 386-391. doi:10.1007/s00421-005-1336-1.

[10] Martin Bland, J., and DouglasG. Altman. "Statistical Methods for Assessing Agreement between Two Methods of Clinical Measurement.” The Lancet 327, no. 8476 (February 1986): 307-310. doi:10.1016/s0140-6736(86)90837-8.

[11] Mcilvoy, Laura. “Comparison of Brain Temperature to Core Temperature.” Journal of Neuroscience Nursing 36, no. 1 (February 2004): 23-31. doi:10.1097/01376517-200402000-00004.

[12] Rumana, Christopher S., Shankar P. Gopinath, Masahiko Uzura, Alex B. Valadka, and Claudia S. Robertson. "Brain Temperature Exceeds Systemic Temperature in Head-Injured Patients." Critical Care Medicine 26, no. 3 (March 1998): $562-567$. doi:10.1097/00003246-199803000-00032.

[13] Bakhsheshi, Mohammad Fazel, Mamadou Diop, Keith St. Lawrence, and Ting-Yim Lee. "Monitoring Brain Temperature by Time-Resolved Near-Infrared Spectroscopy: Pilot Study.” Journal of Biomedical Optics 19, no. 5 (May 9, 2014 ): 057005. doi:10.1117/1.jbo.19.5.057005.

[14] Chung, S H, A E Cerussi, S I Merritt, J Ruth, and B J Tromberg. "Non-Invasive Tissue Temperature Measurements Based on Quantitative Diffuse Optical Spectroscopy (DOS) of Water.” Physics in Medicine and Biology 55, no. 13 (June 15, 2010): 37533765. doi:10.1088/0031-9155/55/13/012.

[15] Weis, Jan, Lucian Covaciu, Sten Rubertsson, Mats Allers, Anders Lunderquist, Francisco Ortiz-Nieto, and Håkan Ahlström. "Phase-Difference and Spectroscopic Imaging for Monitoring of Human Brain Temperature During Cooling." Magnetic Resonance Imaging 30, no. 10 (December 2012): 1505-1511. doi:10.1016/j.mri.2012.06.004.

[16] Fatar, Marc, Mark Stroick, Martin Griebe, Angelika Alonso, Michael G. Hennerici, and Michael Daffertshofer. "Brain Temperature During 340-kHz Pulsed Ultrasound Insonation." Stroke 37, no. 7 (July 2006): $1883-1887$. doi:10.1161/01.str.0000226737.47319.aa.

[17] Karathanasis, Konstantinos T., Ioannis A. Gouzouasis, Irene S. Karanasiou, George Stratakos, and Nikolaos K. Uzunoglu. "Passive Focused Monitoring and Non-Invasive Irradiation of Head Tissue Phantoms at Microwave Frequencies." 2008 8th IEEE International Conference on BioInformatics and BioEngineering (October 2008). doi:10.1109/bibe.2008.4696770.

[18] Yamakage, Michiaki, and Akiyoshi Namiki. "Deep Temperature Monitoring Using a Zero-Heat-Flow Method.” Journal of Anesthesia 17, no. 2 (May 1, 2003): 108-115. doi:10.1007/s005400300026.

[19] Levick, A, D Land, and J Hand. "Validation of Microwave Radiometry for Measuring the Internal Temperature Profile of Human Tissue.” Measurement Science and Technology 22, no. 6 (May 13, 2011): 065801. doi:10.1088/0957-0233/22/6/065801.

[20] Kirk, Danielle, Timothy Rainey, Andy Vail, and Charmaine Childs. "Infra-Red Thermometry: The Reliability of Tympanic and Temporal Artery Readings for Predicting Brain Temperature after Severe Traumatic Brain Injury.” Critical Care 13, no. 3 (2009): R81. doi:10.1186/cc7898. 
[21] Kitamura, Kei-Ichiro, Xin Zhu, Wenxi Chen, and Tetsu Nemoto. "Development of a New Method for the Noninvasive Measurement of Deep Body Temperature Without a Heater.” Medical Engineering \& Physics 32, no. 1 (January 2010): 1-6. doi:10.1016/j.medengphy.2009.09.004.

[22] van der Linden, J, R Ekroth, C Lincoln, W Pugsley, M Scallan, and H Tyden. "Is Cerebral Blood Flow/metabolic Mismatch during Rewarming a Risk Factor after Profound Hypothermic Procedures in Small Children?” European Journal of CardioThoracic Surgery 3, no. 3 (1989): 209-215. doi:10.1016/1010-7940(89)90068-7.

[23] Enomoto, Sakae, Bradley J. Hindman, Franklin Dexter, Tom Smith, and Johann Cutkomp. "Rapid Rewarming Causes an Increase in the Cerebral Metabolic Rate for Oxygen That Is Temporarily Unmatched by Cerebral Blood Flow." Anesthesiology 84, no. 6 (June 1996): 1392-1400. doi:10.1097/00000542-199606000-00016.

[24] Shiozaki, Tadahiko, Hisashi Sugimoto, Mamoru Taneda, Hiroyoshi Yoshida, Atsushi Iwai, Toshiharu Yoshioka, and Tsuyoshi Sugimoto. "Effect of Mild Hypothermia on Uncontrollable Intracranial Hypertension after Severe Head Injury." Survey of Anesthesiology 38, no. 4 (August 1994): 212. doi:10.1097/00132586-199408000-00021.

[25] Povlishock, John T., and Enoch P. Wei. "Posthypothermic Rewarming Considerations Following Traumatic Brain Injury." Journal of Neurotrauma 26, no. 3 (March 2009): 333-340. doi:10.1089/neu.2008.0604.

[26] Rittenberger, Jon C., Stuart Friess, and Kees H. Polderman. "Emergency Neurological Life Support: Resuscitation Following Cardiac Arrest.” Neurocritical Care 23, no. S2 (October 5, 2015): 119-128. doi:10.1007/s12028-015-0171-4.

[27] Peberdy, M. A., C. W. Callaway, R. W. Neumar, R. G. Geocadin, J. L. Zimmerman, M. Donnino, A. Gabrielli, et al. "Part 9: Post-Cardiac Arrest Care: 2010 American Heart Association Guidelines for Cardiopulmonary Resuscitation and Emergency Cardiovascular Care.”Circulation 122, no. 18_suppl_3 (October 17, 2010): S768-S786. doi:10.1161/circulationaha.110.971002.

[28] Fazel Bakhsheshi, Mohammad, Lynn Keenliside, and Ting-Yim Lee. "Rapid and Selective Brain Cooling Method Using Vortex Tube: A Feasibility Study." The American Journal of Emergency Medicine 34, no. 5 (May 2016): 887-894. doi:10.1016/j.ajem.2016.02.001.

[29] Cavallaro, Giacomo, Luca Filippi, Genny Raffaeli, Gloria Cristofori, Federico Schena, Elisa Agazzani, Ilaria Amodeo, et al. "Heart Rate and Arterial Pressure Changes During Whole-Body Deep Hypothermia." ISRN Pediatrics 2013 (2013): 1-6. doi:10.1155/2013/140213.

[30] Tortorici, Michael A., Patrick M. Kochanek, and Samuel M. Poloyac. "Effects of Hypothermia on Drug Disposition, Metabolism, and Response: A Focus of Hypothermia-Mediated Alterations on the Cytochrome P450 Enzyme System." Critical Care Medicine 35, no. 9 (September 2007): 2196-2204. doi:10.1097/01.ccm.0000281517.97507.6e.

[31] Rittenberger, Jon C., Kees H. Polderman, Wade S. Smith, and Scott D. Weingart. "Emergency Neurological Life Support: Resuscitation Following Cardiac Arrest.” Neurocritical Care 17, no. S1 (August 30, 2012): 21-28. doi:10.1007/s12028-0129750-9. 